\section{What All Women Need To Know About Alcohol Con- sumption before and During Pregnancy}

\author{
Margaret Lai and Patricia Diaz* \\ New Life Centre for Women, Sydney, Australia
}

How much Alcohol can you really drink during pregnancy? What sort of complications can drinking cause even before pregnancy?

We often get asked how much alcohol is really safe to consume whilst pregnant. The answer to this question is zero alcohol!

Ever wanted to know how much Alcohol can impact your future's baby overall development including its IQ? And how as little as 2 drinks per week during pregnancy and breastfeeding can cause physical and cognitive defects, including poor growth development to your fetus $[1,2]$ ?

Consuming an average of more than 3 drinks per day before pregnancy is classified to be binge drinking according to a 2014 study in Denmark, and also further discovered excessive consumptions of alcohol can cause neurological and cognitive development disorders in unborn babies, including short attention span, below average IQ levels, affecting their ability to analyze information and solve problems [3].

Binge drinking is also associated with miscarriage, as a 2014 Danish study found that among women who consumed 4 or more drinks per week, 99 women out of 1932 women suffered miscarriage within the first trimester and a further 51 women suffered miscarriage in their second trimester [4].

\section{When You Drink Alcohol, Your Baby Drinks Too}

When a Pregnant woman consumes alcohol, the body breaks it down to form two common compounds namely; acetaldehyde (also known as an agent called Teratogen) and Ethanol which enters the

*Corresponding author: Patricia Diaz, New Life Centre for Women, Suite 10 Level 8 the Dymocks Building, 428 George st, Sydney, NSW, Australia, Tel: +61 0292231882; E-mail: p.diaz@live.com.au

Citation: Lai M, Diaz P (2019) What All Women Need To Know About Alcohol Consumption before and During Pregnancy. J Altern Complement Integr Med 5: 070 .

Received: June 19, 2019; Accepted: June 28, 2019; Published: July 05, 2019

Copyright: @ 2019 Lai M and Diaz P. This is an open-access article distributed under the terms of the Creative Commons Attribution License, which permits unrestricted use, distribution, and reproduction in any medium, provided the original author and source are credited. placenta and is absorbed directly into the defenseless growing fetus, causing birth defects and decreased fetal growth $[5,6]$.

The placenta is one of the most important organs during pregnancy as it helps maintain the fetus and provides a gateway of nutrition between the mother and the unborn baby. Drinking alcohol during pregnancy can impact the overall development of the placenta and cause fetal growth restriction as well, by:

- Restricting blood flow to the placenta

- Causing blood clots in the placenta

- Reducing oxygen and nutrient supply to the placenta and the fetus

- Increasing placental cell death and decrease in cell growth and [7]

- Potentially lead to pre-eclampsia; a serious condition which is responsible for about $18 \%$ of maternal deaths and up to $40 \%$ of fetal mortality worldwide [5].

\section{Can I Drink When I Am Breastfeeding?}

Alcohol not only affects the Placenta but also gets into breast milk by passive diffusion, moving freely from your blood and straight into the baby's body causing interrupted sleep patterns and poor gross motor skills development, such as walking, running, sitting, throwing a ball as found in a Perth, Australian study in 2008 [8].

\section{Can Drinking Cause Birth Defects?}

Even at low levels of prenatal alcohol which amount to be approximately 2 drinks per week can cause physical deformities, behavioral issues and neurocognitive disabilities [1].

A study conducted in California found that for every additional drink pregnant women consumed on top of their average alcohol intake of less than $1 \mathrm{~g}$ of alcohol per day, increased their baby's risk of being born with [9];

- $25 \%$ more likely to have a missing philtrum- a facial deformity where the baby has no groove between the nose and upper lip

- $22 \%$ more likely to have an abnormally thin upper lip

- $18 \%$ more likely to be small in size at birth

- $16 \%$ more likely to weigh less at birth

- $12 \%$ more likely to have microcephaly- a birth defect of an abnormally small head associated with incomplete brain development.

\section{Further Studies Suggest Drinking Affects My Child's Development}

A 2014 study conducted in Britain found that having more than 2 drinks per week during the first trimester can double the baby's chances of being born with 'small for gestational age' causing a defect in a baby's normal birth size and a decrease in birth weight by $100 \mathrm{~g}$. Another 2014 Australian study found that babies born to mothers who drank during pregnancy were $16.8 \%$ more likely to be born pre-mature $[1,10]$. 


\section{Acupuncture}

Preliminary studies support the use of acupuncture to reduce alcohol cravings as discovered in a 2015 Korean study showed the effectiveness of acupuncture point Kidney 9 (Chinese name "ZHUBIN") had on reducing cravings in a group of people with alcohol dependence. The people in this study who were treated with acupuncture experienced significant reduction to alcohol cravings compared to the group that received placebo acupuncture [11].

\section{Take Home Messages Summary}

Alcohol breaks down into:

- Acetaldehyde which can cause birth defects

- Ethanol which restricts nutrient supply and decreases fetal growth

Effects of Alcohol:

- Drinking before and during pregnancy can affect your child's neurodevelopment and impact IQ levels

- Even low level drinking during pregnancy can cause birth defects

- Drinking during pregnancy can decrease birth size and birth weight

- Drinking during pregnancy can cause maternal death and fetal mortality due to pre-eclampsia

- Drinking during breastfeeding affects the development of the child's poor gross motor skills development and interrupted sleep pattern

\section{What Can I Do? Support and Help Lines}

Speak to your GP who can refer you to local support services. For more information, you can contact St Vincent's Alcohol \& Drug Information Service (ADIS) Call: 0293618000 (Confidential \& 24/7 operation) Website: http://yourroom.com.au/

\section{References}

1. Nykajaer et al. 2014

2. Giglia RC, Binns CW (2008) Alcohol pregnancy and breastfeeding a comparison of the 1995 and 2001 National Health Survey data. Breastfeed Rev 16: 17-24.

3. Kesmodel US, Kjaersgaard MI, Denny CH, Bertrand J, Skogerbø Å, et al. (2015) The association of pre-pregnancy alcohol drinking with child neuropsychological functioning. BJOG 122: 1728-1738.

4. Nilson et al. 2014

5. Lui S, Jones RL, Robinson NJ, Greenwood SL, Aplin JD, et al. (2014) Detrimental effects of ethanol and its metabolite, acetaldehyde on first trimester human placental cell turnover and function. PLoS One 9: 87328.

6. Bingham RJ (2015) Latest Evidence on Alcohol and Pregnancy. Nurs Womens Health 19: 338-344.

7. Lui S, Jones RL, Robinson NJ, Greenwood SL, Aplin JD, et al. (2014) Detrimental effects of ethanol and its metabolite, acetaldehyde on first trimester human placental cell turnover and function. PLoS One 9: 87328.

8. Giglia RC, Binns CW, Alfonso HS, Scott JA, Oddy WH (2008) The effect of alcohol intake on breastfeeding duration in Australian women. Acta Paediatr 97: 624-629.

9. Feldman HS, Jones KL, Lindsay S, Slymen D, Klonoff-Cohen H, et al. (2012) Prenatal alcohol exposure patterns and alcohol related birth defects and growth deficiencies: a prospective study. Alcohol Clin Exp Res 36: 670-676.

10. Srikartika VM, O'Leary CM (2015) Pregnancy outcomes of mothers with an alcohol related diagnosis, a population based cohort study for the period of 1983-2007. BJOG 122: 795-804.

11. Lee JS, Kim SG, Jung TG, Jung WY, Kim SY (2015) (KI9) Acupuncture in reducing alcohol craving in patients with alcohol dependence: a randomised placebo-controlled trial. Chin J Integr Med 21: 307-311. 


\section{Hit \\ HERALD}

Journal of Anesthesia \& Clinical Care

Journal of Addiction \& Addictive Disorders

Advances in Microbiology Research

Advances in Industrial Biotechnology

Journal of Agronomy \& Agricultural Science

Journal of AIDS Clinical Research \& STDs

Journal of Alcoholism, Drug Abuse \& Substance Dependence

Journal of Allergy Disorders \& Therapy

Journal of Alternative, Complementary \& Integrative Medicine

Journal of Alzheimer's \& Neurodegenerative Diseases

Journal of Angiology \& Vascular Surgery

Journal of Animal Research \& Veterinary Science

Archives of Zoological Studies

Archives of Urology

Journal of Atmospheric \& Earth-Sciences

Journal of Aquaculture \& Fisheries

Journal of Biotech Research \& Biochemistry

Journal of Brain \& Neuroscience Research

Journal of Cancer Biology \& Treatment

Journal of Cardiology \& Neurocardiovascular Diseases

Journal of Cell Biology \& Cell Metabolism

Journal of Clinical Dermatology \& Therapy

Journal of Clinical Immunology \& Immunotherapy

Journal of Clinical Studies \& Medical Case Reports

Journal of Community Medicine \& Public Health Care

Current Trends: Medical \& Biological Engineering

Journal of Cytology \& Tissue Biology

Journal of Dentistry: Oral Health \& Cosmesis

Journal of Diabetes \& Metabolic Disorders

Journal of Dairy Research \& Technology

Journal of Emergency Medicine Trauma \& Surgical Care

Journal of Environmental Science: Current Research

Journal of Food Science \& Nutrition

Journal of Forensic, Legal \& Investigative Sciences

Journal of Gastroenterology \& Hepatology Research

Journal of Gerontology \& Geriatric Medicine

Journal of Genetics \& Genomic Sciences

Journal of Hematology, Blood Transfusion \& Disorders

Journal of Human Endocrinology

Journal of Hospice \& Palliative Medical Care

Journal of Internal Medicine \& Primary Healthcare

Journal of Infectious \& Non Infectious Diseases

Journal of Light \& Laser: Current Trends

Journal of Modern Chemical Sciences

Journal of Medicine: Study \& Research

Journal of Nanotechnology: Nanomedicine \& Nanobiotechnology

Journal of Neonatology \& Clinical Pediatrics

Journal of Nephrology \& Renal Therapy

Journal of Non Invasive Vascular Investigation

Journal of Nuclear Medicine, Radiology \& Radiation Therapy

Journal of Obesity \& Weight Loss

Journal of Orthopedic Research \& Physiotherapy

Journal of Otolaryngology, Head \& Neck Surgery

Journal of Protein Research \& Bioinformatics

Journal of Pathology Clinical \& Medical Research

Journal of Pharmacology, Pharmaceutics \& Pharmacovigilance

Journal of Physical Medicine, Rehabilitation \& Disabilities

Journal of Plant Science: Current Research

Journal of Psychiatry, Depression \& Anxiety

Journal of Pulmonary Medicine \& Respiratory Research

Journal of Practical \& Professional Nursing

Journal of Reproductive Medicine, Gynaecology \& Obstetrics

Journal of Stem Cells Research, Development \& Therapy

Journal of Surgery: Current Trends \& Innovations

Journal of Toxicology: Current Research

Journal of Translational Science and Research

Trends in Anatomy \& Physiology

Journal of Vaccines Research \& Vaccination

Journal of Virology \& Antivirals

Archives of Surgery and Surgical Education

Sports Medicine and Injury Care Journal

International Journal of Case Reports and Therapeutic Studies 